\title{
Copy number variations of the ATP-binding cassette transporter $A B C C 6$ gene and its pseudogenes
}

Marianne K Kringen ${ }^{1 *}$, Camilla Stormo ${ }^{2}$, Runa M Grimholt ${ }^{2}$, Jens P Berg ${ }^{2}$ and Armin P Piehler ${ }^{2,3}$

\begin{abstract}
Background: The ATP-binding cassette transporter ABCC6 gene is located on chromosome 16 between its two pseudogenes (ABCC6P1 and $A B C C 6 P 2)$. Previously, we have shown that $A B C C 6 P 1$ is transcribed and affects $A B C C 6$ at the transcriptional level. In this study we aimed to determine copy number variations of $A B C C 6, A B C C 6 P 1$ and $A B C C 6 P 2$ in different populations. Moreover, we sought to study the transcription pattern of $A B C C 6$ and $A B C C 6$ pseudogenes in 39 different human tissues.

Findings: Genomic DNA from healthy individuals from five populations, Chinese $(n=24)$, Middle East $(n=20)$, Mexicans $(n=24)$, Caucasians $(n=50)$ and Africans $(n=24)$, were examined for copy number variations of $A B C C 6$ and its pseudogenes by pyrosequencing and quantitative PCR. Copy number variation of $A B C C 6$ was very rare $(2 / 142 ; 1.4 \%)$. However, one or three copies of $A B C C 6 P 1$ were relatively common ( $3 \%$ and $8 \%$, respectively). Only one person had a single copy of $A B C C 6 P 2$ while none had three copies. In Chinese, deletions or duplications of ABCC6P1 were more frequent than in any other population $(9 / 24 ; 37.5 \%)$. The transcription pattern of $A B C C 6 P 2$ was highly similar to $A B C C 6$ and $A B C C 6 P 1$, with highest transcription in liver and kidney. Interestingly, the total transcription level of pseudogenes, $A B C C 6 P 1+A B C C 6 P 2$, was higher than $A B C C 6$ in most tissues, including liver and kidney.
\end{abstract}

Conclusions: Copy number variations of the $A B C C 6$ pseudogenes are quite common, especially in populations of Chinese ancestry. The expression pattern of ABCC6P2 in 39 human tissues was highly similar to that of $A B C C 6$ and $A B C C 6 P 1$ suggesting similar regulatory mechanisms for $A B C C 6$ and its pseudogenes.

Keywords: Copy number variation, $A B C C 6$, Pseudogenes, Pyrosequencing, Transcription

\section{Findings \\ Background}

The ATP-binding cassette transporter ABCC6 belongs to a large family of membrane proteins ( $A B C$ transporters) that are a highly conserved and present in all organisms from bacteria to man [1,2]. The ABCC6 gene (Entrez Gene ID 368) is located on the short arm of chromosome 16 along with two shorter, almost identical (> 99\% sequence identity), pseudogenes; $A B C C 6 P 1$ (Entrez Gene ID 653190) and ABCC6P2 (Entrez Gene ID 730013) (Figure 1) [3]. Pseudogenes are generally defined as non-functional genes, meaning that they usually do not produce a transcript or a functional protein

\footnotetext{
* Correspondence: m.k.kringen@medisin.uio.no

'Department of Pharmacology, Oslo University Hospital, Ullevål, P.O. Box 4956 Nydalen, 0424 Oslo, Norway

Full list of author information is available at the end of the article
}

[4,5]. Transcription of $A B C C 6$ pseudogenes have been described $[3,6,7]$, and recently we found strong evidence for a regulatory interdependency between $A B C C 6$ and its pseudogene $A B C C 6 P 1$ [7].

Mutations and deletions in $A B C C 6$ are known to cause the rare (prevalence between 1:25,000 and 1:100,000), autosomal recessive disease pseudoxanthoma elasticum (PXE, OMIM 264800), a metabolic disorder characterized by ectopic mineralization of soft connective tissues $[8,9]$. ABCC6 is located on chromosome 16, a known hotspot of chromosomal instability, showing several genomic duplications and deletions (generally called copy number variations) $[10,11]$. We therefore hypothesized that $A B C C 6$ pseudogenes would be liable to chromosomal rearrangements and thereby subject to copy number variations. Having less or more copies of $A B C C 6$ pseudogenes is likely to influence the expression level of
Ciomed Central

(c) 2012 Kringen et al.; licensee BioMed Central Ltd. This is an Open Access article distributed under the terms of the Creative Commons Attribution License (http://creativecommons.org/licenses/by/2.0), which permits unrestricted use, distribution, and reproduction in any medium, provided the original work is properly cited. 


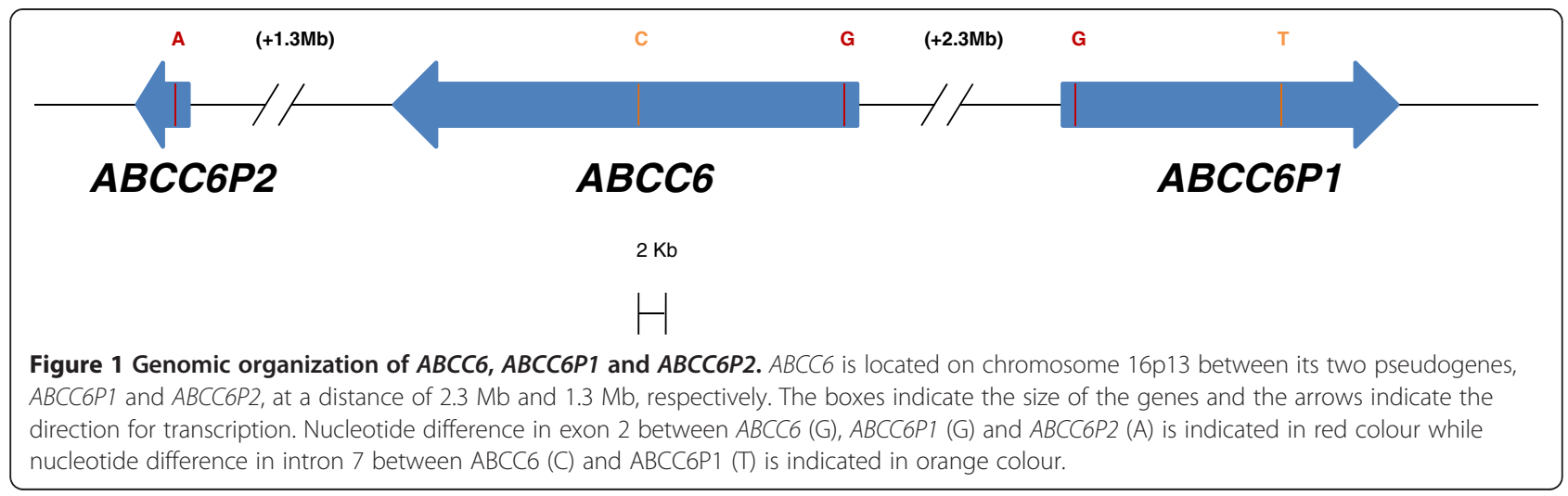

these pseudogenes, and thus, may have an impact on the parent gene $A B C C 6$, including the genetic message, the protein level and the function of the protein.

Estimation of copy number variations and transcription of pseudogenes is generally difficult because of the high sequence similarity between pseudogenes and their parent genes. However, pyrosequencing has recently shown to be a helpful tool to differentiate between highly similar genes by only one nucleotide difference [12]. Therefore, principally by the use of pyrosequencing, the aim of this study was to determine copy number variations of $A B C C 6, A B C C 6 P 1$ and $A B C C 6 P 2$. Moreover, we sought to study the mRNA transcription pattern of $A B C C 6, A B C C 6 P 1$ and $A B C C 6 P 2$ in 39 different human tissues.

\section{Results}

\section{Copy number variations in ABCC6 and its pseudogenes in} human samples

Copy number variation of $A B C C 6$ was very rare (2/142; $1.4 \%$ ) (Table 1) in healthy individuals. No individuals had deletions of $A B C C 6$. Deviation in copy number was more frequent for $A B C C 6$ pseudogenes. In Chinese, deletions or duplications of $A B C C 6 P 1$ were more frequent than in any other population $(9 / 24 ; 37.5 \%)$. Furthermore, in the total population $(n=142)$, one or three copies of $A B C C 6 P 1$ was relatively common (3\% and $8 \%$, respectively). Only one person had one copy of $A B C C 6 P 2$ while none had three copies. In Africans, however, no copy number variation was found for ABCC6 pseudogenes. All the members of two Centre d'Etude du Polymorphisme Humain (CEPH) pedigrees had two copies of $A B C C 6, A B C C 6 P 1$ and $A B C C 6 P 2$ (data not shown). As copy number variation was analyzed in short specific regions of $A B C C 6$ and $A B C C 6$ pseudogenes, small deletions/insertions in other regions of these genes cannot be excluded.

\section{Gene expression of $A B C C 6$ and its pseudogenes in human samples}

$A B C C 6$ and ABCC6 pseudogene expression profiling was performed in various human tissues (not corresponding to individuals analyzed for copy number variations). The transcription pattern of $A B C C 6 P 2$ was highly similar to $A B C C 6$ and $A B C C 6 P 1$, with highest transcription in liver and kidney (Figure $2 \mathrm{~A}-\mathrm{C}$ ). Interestingly, the total mRNA level of $A B C C 6$ pseudogenes, $A B C C 6 P 1+$ $A B C C 6 \mathrm{P} 2$, was higher than $A B C C 6 \mathrm{mRNA}$ levels in

Table 1 Copy number variation in different populations

\begin{tabular}{|c|c|c|c|c|c|c|c|}
\hline \multirow[t]{2}{*}{ Genes } & \multirow[t]{2}{*}{ Copies } & \multirow{2}{*}{$\begin{array}{c}\begin{array}{c}\text { Caucasians } \\
(\mathrm{N}=50)\end{array} \\
\mathrm{N}(\%)\end{array}$} & \multirow{2}{*}{$\begin{array}{c}\begin{array}{c}\text { Mexicans } \\
(\mathrm{N}=24)\end{array} \\
\mathrm{N}(\%)\end{array}$} & \multirow{2}{*}{$\begin{array}{c}\begin{array}{c}\text { Middle-East } \\
(\mathrm{N}=20)\end{array} \\
\mathrm{N}(\%)\end{array}$} & \multirow{2}{*}{$\begin{array}{c}\begin{array}{c}\text { Africans } \\
(\mathrm{N}=24)\end{array} \\
\mathrm{N}(\%)\end{array}$} & \multirow{2}{*}{$\begin{array}{l}\text { Chinese } \\
(\mathrm{N}=24) \\
\mathrm{N}(\%)\end{array}$} & \multirow{2}{*}{$\begin{array}{c}\begin{array}{c}\text { Total } \\
(\mathrm{N}=142)\end{array} \\
\mathrm{N}(\%)\end{array}$} \\
\hline & & & & & & & \\
\hline \multirow[t]{3}{*}{$A B C C 6$} & 1 & $0(0)$ & $0(0)$ & $0(0)$ & $0(0)$ & $0(0)$ & $0(0)$ \\
\hline & 2 & $50(100)$ & $23(96)$ & $20(100)$ & $24(100)$ & $23(96)$ & $140(99)$ \\
\hline & 3 & $0(0)$ & $1(4)$ & $0(0)$ & $0(0)$ & $1(4)$ & $2(1)$ \\
\hline \multirow[t]{3}{*}{$A B C C 6 P 1$} & 1 & $0(0)$ & $0(0)$ & $1(5)$ & $0(0)$ & $4(17)$ & $5(3)$ \\
\hline & 2 & $47(94)$ & $23(96)$ & $17(85)$ & $24(100)$ & $15(62)$ & $126(89)$ \\
\hline & 3 & $3(6)$ & $1(4)$ & $2(10)$ & $0(0)$ & $5(21)$ & $11(8)$ \\
\hline \multirow[t]{3}{*}{$A B C C 6 P 2$} & 1 & $0(0)$ & $0(0)$ & $0(0)$ & $0(0)$ & $1(4)$ & $1(1)$ \\
\hline & 2 & $50(100)$ & $24(100)$ & $20(100)$ & $24(100)$ & $23(96)$ & $141(99)$ \\
\hline & 3 & $0(0)$ & $0(0)$ & $0(0)$ & $0(0)$ & $0(0)$ & $0(0)$ \\
\hline
\end{tabular}



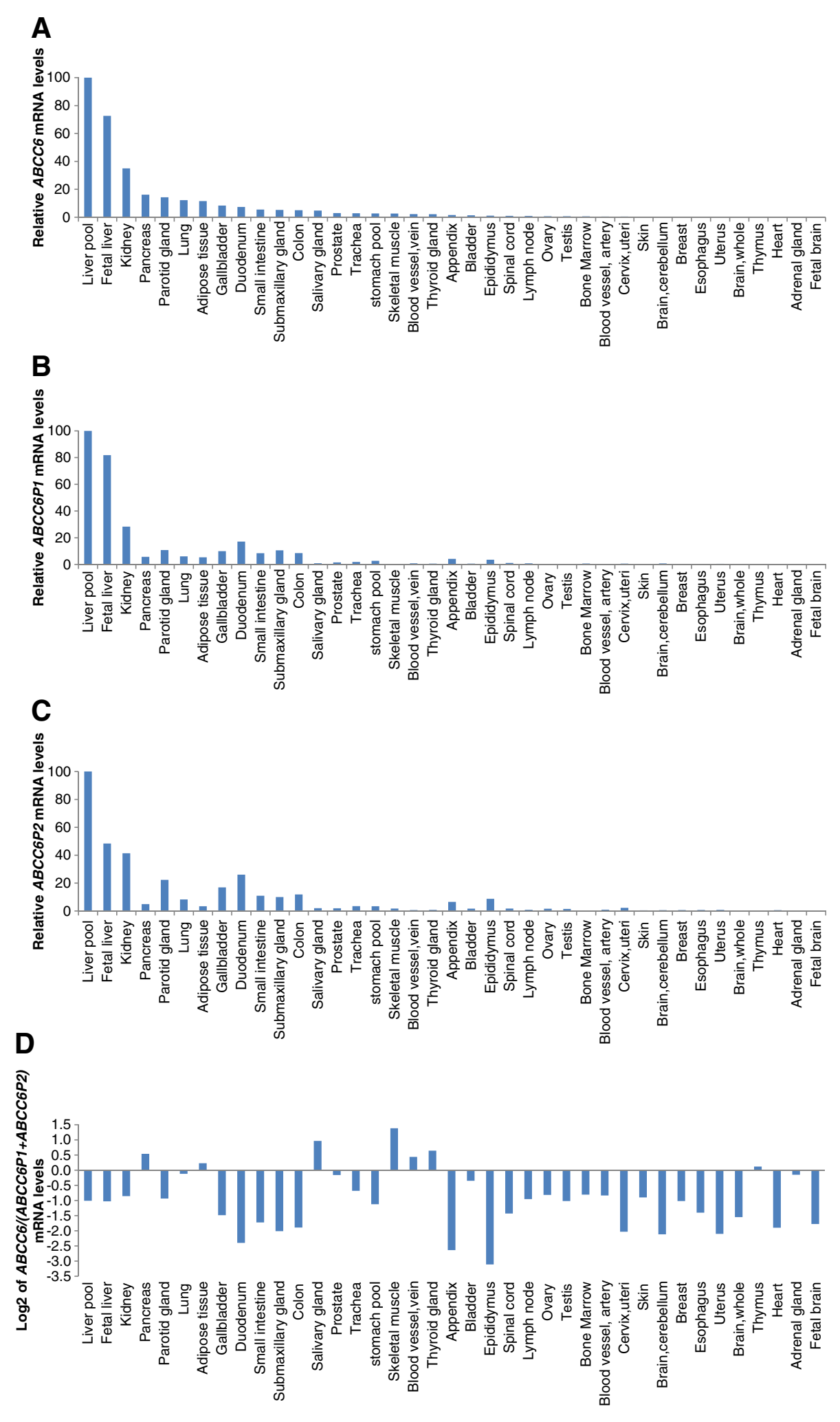

Figure 2 mRNA expression of $A B C C 6$ and its pseudogenes $A B C C 6 P 1$ and $A B C C 6 P 2$ in a variety of human tissues. Relative normalized transcription of $A B C C 6(\mathbf{A}), A B C C 6 P 1$ (B) and $A B C C 6 P 2$ (C) in 39 human tissues. The tissue with the highest expression (liver pool) was used as reference tissue (100\%). (D) Expression of $A B C C 6$ relative to $A B C C 6 P 1$ and $A B C C 6 P 2$. Ratios are shown as a logarithmic scale (base 2). 
most tissues, including liver and kidney (Figure $2 \mathrm{D}$ ). However, it should be noted that in tissues with low $A B C C 6$ mRNA levels, differences in expression between $A B C C 6$ and its pseudogenes may result from stochastic effects during the PCR.

\section{Discussion}

In this study, we found copy number variation of ABCC6 pseudogenes to be frequent, especially in populations of Chinese ancestry. However, as expected in healthy populations, no individuals had deletions of $A B C C 6 . A B C C 6$ and its pseudogenes, with their high sequence identity $(>99 \%)$, represent a low copy repeat (LCR). LCRs are paralogue segments of usually $>10 \mathrm{~kb}$ with $>97 \%$ sequence identity and can act as substrates for nonallelic homologous recombination which may lead to deletion, duplication or inversion of the intervening sequence $[13,14]$. Phylogenetic trees on human and chimpanzee sequences show that $A B C C 6$ pseudogenes have occurred independently several times in these species, which further demonstrate the high mobility of these genes [15]. Our results confirm the hypothesis that $A B C C 6$ pseudogenes would be liable to genomic instability and thereby copy number variations.

Six percent of Caucasians are expected to have three copies of ABCC6P1 (Table 1). However, none of the 35 members of two 3-generation-pedigrees (CEPH pedigrees) had deviation from the normal copy of two of $A B C C 6$ or $A B C C 6$ pseudogenes, indicating a Mendelian transmission of these copy numbers and that de novo deletion/duplication of pseudogenes do not arise frequently.

$A B C C 6$ and its pseudogenes share highly similar proximal promoter sequences (> 98.5\% sequence identity) [7]. Furthermore, the hepatocyte nuclear factor $4 \alpha$ (HNF4 $\alpha$ ) binding site located at $-166 /-154$ of the $A B C C 6$ promoter, which is crucial for tissue-specific expression pattern of $A B C C 6[16,17]$, is also present in the $A B C C 6 P 1$ and $A B C C 6 P 2$ promoters. Thus, the finding of similar expression pattern for $A B C C 6$ and both pseudogenes in human tissues strongly imply similar regulatory mechanisms for $A B C C 6$ and its pseudogenes. On the other hand, these results also suggest that both $A B C C 6$ - and $A B C C 6$ pseudogene transcripts have similar half-lives, which is surprising since they do not share the same mRNA 3'-ends. Pseudogenes were for a long time assumed to be "junk DNA". However, recent studies have shown that many pseudogenes are functionally active and that they may influence their parent gene [7,18-23], and potential mechanisms of pseudogene function have been suggested. Copy number variation in pseudogenes has previously also been identified for the Neutrophil cytosolic factor 1 (NCF1) pseudogenes [2426]. NCF1 is a component of NADPH oxidase and having fewer or more copies of NCF1 pseudogenes seem to influence the production of reactive oxygen intermediates $[24,26]$. It would therefore be interesting to investigate whether different copy numbers of $A B C C 6$ pseudogenes also influences the expression of the $A B C C 6$ gene. Unfortunately, the expression of $A B C C 6$, $A B C C 6 P 1$ and $A B C C 6 P 2$ in various human lymphoblastoid cell lines with one, two or three copies of $A B C C 6 P 1$, which could be used for these studies, was too low to be detected by reverse transcription - quantitative real-time PCR (RT-qPCR) or pyrosequencing (data not shown).

\section{Methods}

\section{Human samples}

Genomic DNA from the National Institute of General Medical Science (NIGMS) Human Variation Panels was purchased from the Coriell Cell Repositories (Camden, USA): The Caucasian Panel $(\mathrm{n}=50)$; The Han People of Los Angeles Panel $(\mathrm{n}=24)$; The Middle Eastern Panel, version 1 and 2, $(n=20)$; The Mexican-American Community of Los Angeles Panel $(n=24)$, The AfricanAmerican Panel $(n=24)$ and two pedigrees $(C E P H / U t a h$ Pedigree 1331 and CEPH/Amish Pedigree 884). High quality RNA samples of the Human Total Master panel II and the Human Adult Normal Tissue Total RNA (39 tissues in total) were purchased from Clontech (Mountain View, USA) and BioCat Gmbh (Heidelberg, Germany) respectively.

\section{Copy number variation analysis}

For absolute copy number determination of $A B C C 6$, the TaqMan ${ }^{\circledR}$ Copy Number Assay was used targeting ABCC6 specifically in intron 11 (Hs03952142_cn; Applied Biosystems, Foster City, USA). Rnase P, which is known to be present in two copies in the human genome, was used as endogenous reference gene (TaqMan ${ }^{\circledR}$ Copy Number Reference Assay Rnase P, Applied Biosystems). The ABCC6 assay (labeled with FAM), the RnaseP assay (labeled with VIC), sample DNA and 2xTaqMan Universal PCR Master Mix was combined in $20 \mu \mathrm{l}$ reactions and ran in quadruplicate on a 7900HT Fast RealTime PCR System using standard conditions (Applied Biosystem). The absolute copy number of ABCC6 was thereby calculated using CopyCaller ${ }^{\mathrm{Tm}}$ Software v1.0 (Applied Biosystems).

For pyrosequencing, two sets of PCR primers were designed to amplify ABCC6, ABCC6P1 and $A B C C 6 P 2$. The first set of primers targeted intron 7 of $A B C C 6$ and $A B C C 6 P 1$ only, while the other set of primers targeted exon 2 of all three genes (Table 2 and Figure 1). The genes were amplified from $\sim 100 \mathrm{ng}$ of genomic DNA in $25 \mu \mathrm{L}$ reactions using $1 \times$ PyroMark PCR Master Mix, 1 $x$ CoralLoad Concentrate (Qiagen, Venlo, The Netherlands) and $0.2 \mu \mathrm{M}$ primers. Cycling conditions were an 
Table 2 Primer sequences and nucleotide dispensation order used in pyrosequencing assays

\begin{tabular}{|c|c|c|c|c|c|c|}
\hline \multirow[t]{2}{*}{ Assay \# } & \multirow[t]{2}{*}{ Genes } & \multirow[t]{2}{*}{ Template } & \multirow[t]{2}{*}{ Primer } & \multirow[t]{2}{*}{ Sequence } & Dispensation order & \multirow[t]{2}{*}{ Amplicon size (bp } \\
\hline & & & & & 123456789 & \\
\hline \multirow[t]{3}{*}{1} & $A B C C 6-A B C C 6 P 1$ & gDNA & Forward & 5'-TGAGGGAGCCAGGCTAGA-3' & & 129 \\
\hline & & & Reverse & 5'-Biotin-GAGGGGAAGGGAGAGATTAGC-3' & & \\
\hline & & & Sequencing & 5'-GCCTGGCCCTGCCGC-3' & GTAGCTGCI & \\
\hline \multirow[t]{3}{*}{2} & $A B C C 6-A B C C 6 P 1-A B C C 6 P 2$ & gDNA & Forward & 5'-Biotin-TCCCATCTACCTCCTCTTCATC-3' & & 76 \\
\hline & & & Reverse & 5'ATCTTGGCTTTGAAGAGTGG-3' & & \\
\hline & & & Sequencing & 5'-TGGCTTTGAAGAGTGG-3' & CGACATCI & \\
\hline \multirow[t]{3}{*}{3} & $A B C C 6-A B C C 6 P 1-A B C C 6 P 2$ & CDNA & Forward & 5'-Biotin-CGGGGCAGGGGGTCTGGAAC-3' & & 195 \\
\hline & & & Reverse & 5'-ATCTTGGCTTTGAAGAGTGG-3' & & \\
\hline & & & Sequencing & 5'-TGGCTTTGAAGAGTGG-3' & CGACATCT & \\
\hline
\end{tabular}

initial enzyme activation step at $95^{\circ} \mathrm{C}$ for $15 \mathrm{~min}$ and 45 cycles of $94^{\circ} \mathrm{C}$ for $30 \mathrm{~s}, 60^{\circ} \mathrm{C}$ for $30 \mathrm{~s}$, and $72^{\circ} \mathrm{C}$ for $30 \mathrm{~s}$, and a final extension cycle of $72^{\circ} \mathrm{C}$ for $10 \mathrm{~min}$. Twenty micro liter of PCR products were added to 40 $\mu \mathrm{L}$ Binding Buffer (Qiagen), $2 \mu \mathrm{L}$ streptavidin sepharose high-performance beads (GE Healthcare, Little Chalfont, United Kingdom) and $18 \mu \mathrm{L}$ water and stirred for 5$10 \mathrm{~min}$ at $1400 \mathrm{rpm}$ on a mixer. Single stranded biotinylated templates were isolated using PyroMark Vacuum Prep WorkStation (Qiagen) and dispensed onto PyroMarkQ24 plate containing $25 \mu \mathrm{L}$ of $0.3 \mu \mathrm{M}$ sequencing primer and Annealing Buffer (Qiagen). The plates were incubated for $2 \mathrm{~min}$ at $80^{\circ} \mathrm{C}$ and subsequently cooled at room temperature for at least $5 \mathrm{~min}$. Sequencing was performed using a PyroMark Q24 instrument with PyroGold reagents (Qiagen). In the sequencing reaction, one and one nucleotide is added at the time, and peak heights are propotional to the amount of nucleotide molecules incorporated. Therefore, relative copy numbers were calculated using ratios of pyrogram peak heights: $A B C C 6 /(A B C C 6+A B C C 6 P 1)=C 5 / C 8 \quad(C 5$ and $\mathrm{C} 8$ being the peak heights at dispensation 5 and 8 , respectively for assay \#1) and $A B C C 6 P 2 /(A B C C 6+$ $A B C C 6 \mathrm{P} 1+A B C C 6 \mathrm{P} 2)=\mathrm{T} 8 / \mathrm{T} 6$ (T6 and $\mathrm{T} 8$ being the peak heights at dispensation 6 and 8 , respectively for assay \# 2, note; reverse sequencing) (Table 2).

The absolute copy number for each allele ( $A B C C 6$, $A B C C 6 P 1$ and $A B C C 6 P 2)$ was finally deduced from the TaqMan ${ }^{\circledR}$ Copy Number Assay and the two pyrosequencing assays.

\section{Gene expression analysis}

cDNA was synthesized from total RNA from 39 tissues $(1 \mu \mathrm{g})$ by reverse-transcription using Omniscript RT kit (Qiagen) in the presence of oligo-dT and random hexamer primers (Applied Biosystems) in $20 \mu \mathrm{L}$ reactions.

Previously, the mRNA expression pattern of $A B C C 6$ and $A B C C 6 P 1$ in 20 different tissues was described by our group [7]. In this study, we determined the mRNA expression pattern of $A B C C 6$ and $A B C C 6 P 1$ in a total of 39 tissues by RT-qPCR on a 7900HT Fast Real-Time PCR System (Applied Biosystems). Five of twelve reference genes were estimated by geNorm [27] to give the most reliable normalization factors (see [28] for assay IDs): $G A P D H=P G K 1>S D H A>C T B P 1>G O L G A 1$. The expression of $A B C C 6$ and $A B C C 6 P 1$ was normalized to these factors for each tissue.

Due to methodological issues, the mRNA expression pattern of $A B C C 6 P 2$ was not investigated in our previous study [7]. In this study, the relative mRNA expression pattern of $A B C C 6 P 2$ was analyzed by pyrosequencing. Primers for mRNA expression were designed to amplify $A B C C 6, A B C C 6 P 1$ and $A B C C 6 P 2$ expressed genes (Table 2). The relative transcription of $A B C C 6 P 2$ to $A B C C 6$ and $A B C C 6 P 1$ in the same 39 tissues was quantified using the same equation as above: $A B C C 6 P 2 /(A B C C 6+A B C C 6 P 1+A B C C 6 P 2)=\mathrm{T} 8 /$ T6; Assay \#3, Table 2), and by using the expressional data (RT-qPCR) of $A B C C 6$ and $A B C C 6 P 1$. All PCR samples were run in parallels. No parallels varied more than 0.5 quantification cycles in qPCR experiments or 0.1 in pyrosequencing peak height ratios.

\section{Availability of supporting data}

The data set supporting the results of this article are included within the article in Additional file 1 Table S1.

\section{Additional file}

Additional file 1: Table S1. Copy numbers of ABCC6, ABCC6P1 and ABCC6P2.

Competing interests

The authors declare that they have no competing interests.

\section{Authors' contributions}

MKK, AP and JPB participated in the study design. MKK, CS and RMG carried out the experimental work. MKK and CS did the interpretation of data. MKK drafted the manuscript with assistance from CS and AP. All authors read and approved the final manuscript. 


\section{Acknowledgements}

This project has been financed with aid from the South-Eastern Norway Regional Health Authority and grant from the Clinic of Diagnostics and Intervention, Oslo university hospital, Oslo, Norway.

\section{Author details}

${ }^{1}$ Department of Pharmacology, Oslo University Hospital, Ullevål, P.O. Box 4956 Nydalen, 0424 Oslo, Norway. ²Department of Medical Biochemistry, Oslo University Hospital, Ullevål, P.O. Box 4956 Nydalen, 0424 Oslo, Norway. ${ }^{3}$ Furst Medical Laboratory, Søren Bullsvei 25, 1051 Oslo, Norway.

Received: 24 February 2012 Accepted: 1 August 2012

Published: 9 August 2012

\section{References}

1. Higgins CF: ABC transporters: from microorganisms to man. Annu Rev Cell Biol 1992, 8:67-113.

2. Holland IB, Cole SPC, Kuchler K, Higgins CF: ABC Proteins: From Bacteria to Man. 1st edition. London: Academic Press; 2002.

3. Pulkkinen L, Nakano A, Ringpfeil F, Uitto J: Identification of ABCC6 pseudogenes on human chromosome $16 \mathrm{p}$ : implications for mutation detection in pseudoxanthoma elasticum. Hum Genet 2001, 109:356-365.

4. Mighell AJ, Smith NR, Robinson PA, Markham AF: Vertebrate pseudogenes. FEBS Lett 2000, 468:109-114.

5. Balakirev ES, Ayala FJ: Pseudogenes: are they "junk" or functional DNA? Annu Rev Genet 2003, 37:123-151.

6. Aranyi T, Ratajewski M, Bardoczy V, Pulaski L, Bors A, Tordai A, et al: Identification of a DNA methylation-dependent activator sequence in the pseudoxanthoma elasticum gene, ABCC6. J Biol Chem 2005, 280:18643-18650.

7. Piehler AP, Hellum M, Wenzel JJ, Kaminski E, Haug KB, Kierulf P, et al: The human $A B C$ transporter pseudogene family: Evidence for transcription and gene-pseudogene interference. BMC Genomics 2008, 9:165.

8. Costrop LM, Vanakker OO, Van LL, Le SO, Martin L, Chassaing N, et al: Novel deletions causing pseudoxanthoma elasticum underscore the genomic instability of the ABCC6 region. J Hum Genet 2010, 55:112-117.

9. Uitto J, Li Q, Jiang Q: Pseudoxanthoma elasticum: molecular genetics and putative pathomechanisms. J Invest Dermatol 2010, 130:661-670.

10. Sharp AJ, Hansen S, Selzer RR, Cheng Z, Regan R, Hurst JA, et al: Discovery of previously unidentified genomic disorders from the duplication architecture of the human genome. Nat Genet 2006, 38:1038-1042.

11. Redon R, Ishikawa S, Fitch KR, Feuk L, Perry GH, Andrews TD, et al: Global variation in copy number in the human genome. Nature 2006, 444:444-454.

12. Ahmadian A, Gharizadeh B, Gustafsson AC, Sterky F, Nyren P, Uhlen M, et al: Single-nucleotide polymorphism analysis by pyrosequencing. Anal Biochem 2000, 280:103-110.

13. Bailey JA, Gu Z, Clark RA, Reinert K, Samonte RV, Schwartz S, et al: Recent segmental duplications in the human genome. Science 2002, 297:1003-1007.

14. Stankiewicz P, Lupski JR: Genome architecture, rearrangements and genomic disorders. Trends Genet 2002, 18:74-82.

15. Symmons O, Varadi A, Aranyi T: How segmental duplications shape our genome: recent evolution of ABCC6 and PKD1 Mendelian disease genes. Mol Biol Evol 2008, 25:2601-2613.

16. Ratajewski M, de Boussac H, Pulaski L: Liver-specific enhancer in ABCC6 promoter-Functional evidence from natural polymorphisms. Biochem Biophys Res Commun 2009, 383:73-77.

17. de Boussac H, Ratajewski M, Sachrajda I, Koblos G, Tordai A, Pulaski L et al: The ERK1/2-hepatocyte nuclear factor 4alpha axis regulates human ABCC6 gene expression in hepatocytes. J Biol Chem 2010, 285:22800-22808.

18. Pink RC, Wicks K, Caley DP, Punch EK, Jacobs L, Carter DR: Pseudogenes: pseudo-functional or key regulators in health and disease? RNA 2011, 17:792-798.

19. Watanabe T, Totoki Y, Toyoda A, Kaneda M, Kuramochi-Miyagawa S, Obata $Y$, et al: Endogenous siRNAs from naturally formed dsRNAs regulate transcripts in mouse oocytes. Nature 2008, 453:539-543.

20. Tam OH, Aravin AA, Stein P, Girard A, Murchison EP, Cheloufi S, et al: Pseudogene-derived small interfering RNAs regulate gene expression in mouse oocytes. Nature 2008, 453:534-538.
21. Piehler AP, Haug KB, Wenzel JJ, Kierulf PB, Kaminski WE: ABCA-transporters: regulators of cellular lipid transport. Tidsskr Nor Laegeforen 2007, 127:2930-2933.

22. Duret $L$, Chureau C, Samain S, Weissenbach J, Avner P: The Xist RNA gene evolved in eutherians by pseudogenization of a protein-coding gene. Science 2006, 312:1653-1655.

23. Muro EM, Mah N, Andrade-Navarro MA: Functional evidence of posttranscriptional regulation by pseudogenes. Biochimie 2011, 93:1916-1921.

24. Greve B, Hoffmann P, Vonthein R, Kun J, Lell B, Mycko MP, et al: NCF1 gene and pseudogene pattern: association with parasitic infection and autoimmunity. Malar J 2008, 7:251.

25. Brunson T, Wang Q, Chambers I, Song Q: A copy number variation in human NCF1 and its pseudogenes. BMC Genet 2010, 11:13.

26. Olsson LM, Nerstedt A, Lindqvist AK, Johansson SC, Medstrand P, Olofsson $P$, et al: Copy number variation of the gene NCF1 is associated with rheumatoid arthritis. Antioxid Redox Signal 2012, 16:71-78.

27. Vandesompele J, de Preter K, Pattyn F, Poppe B, van Roy N, de Paepe A, et al: Accurate normalization of real-time quantitative RT-PCR data by geometric averaging of multiple internal control genes. Genome Biol 2002, 3: RESEARCH0034.

28. Piehler AP, Grimholt RM, Ovstebo R, Berg JP: Gene expression results in lipopolysaccharide-stimulated monocytes depend significantly on the choice of reference genes. BMC Immunol 2010, 11:21.

doi:10.1186/1756-0500-5-425

Cite this article as: Kringen et al:: Copy number variations of the ATPbinding cassette transporter $A B C C 6$ gene and its pseudogenes. $B M C$ Research Notes 2012 5:425.

\section{Submit your next manuscript to BioMed Central and take full advantage of:}

- Convenient online submission

- Thorough peer review

- No space constraints or color figure charges

- Immediate publication on acceptance

- Inclusion in PubMed, CAS, Scopus and Google Scholar

- Research which is freely available for redistribution

Submit your manuscript at www.biomedcentral.com/submit
C) Biomed Central 